\title{
Cognition and Incident Dementia Hospitalization: Results from the Atherosclerosis Risk in Communities Study
}

\author{
Andrea L.C. Schneider ${ }^{a}$ b Rebecca F. Gottesman ${ }^{a, c}$ Thomas Mosley ${ }^{d}$ \\ Alvaro Alonso $^{\text {e David S. Knopman }}{ }^{f}$ Josef Coresh ${ }^{a, b}$ A. Richey Sharrett ${ }^{a, b}$ \\ Elizabeth Selvin ${ }^{a, b}$ \\ a Department of Epidemiology, Bloomberg School of Public Health, ${ }^{b}$ Welch Center for Prevention, Epidemiology, \\ and Clinical Research, and ' Department of Neurology, School of Medicine, Johns Hopkins University, \\ Baltimore, Md., 'd Department of Medicine, University of Mississippi Medical Center, Jackson, Miss., \\ e Division of Epidemiology and Community Health, School of Public Health, University of Minnesota, \\ Minneapolis, Minn., and fDepartment of Neurology, Mayo Clinic, Rochester, Minn., USA
}

\section{Key Words}

Cognition • Dementia • Hospitalizations • Cognitive

function - Cognitive decline

\begin{abstract}
Background/Aims: Cognitive decline is a defining feature of dementia. We sought to determine if a single baseline cognitive test score or change in test score over time is more strongly associated with risk of dementia hospitalization. We also sought to compare short- and long-term dementia risk. Methods: Prospective cohort study of 9,399 individuals from the Atherosclerosis Risk in Communities Study (median 10 years of follow-up). Cognition was assessed at two time points (6 years apart) using three tests: Delayed Word Recall Test (DWRT), Digit Symbol Substitution Test (DSST), and Word Fluency Test. Dementia hospitalizations were determined using ICD-9 codes. Results: Baseline cognitive test scores were associated with both short-term and long-term risk of dementia. The association of 6-year change in cognitive test score with dementia risk was stronger than that of individual test scores at a single visit [change from highest to lowest tertile, DWRT: hazard ratio $=6.45$ (95\% confidence in-
\end{abstract}

\section{KARGER}

Fax +4161306 1234

E-Mail karger@karger.ch

www.karger.com
(C) 2012 S. Karger AG, Basel

$0251-5350 / 13 / 0402-0117 \$ 38.00 / 0$

Accessible online at:

www.karger.com/ned terval $=1.80-23.08) ;$ DSST: hazard ratio $=10.94(95 \%$ confidence interval $=3.07-38.97)]$. Conclusions: In this community-based population, 6-year changes in cognitive scores were more strongly associated with risk of incident dementia hospitalization than baseline scores, although single DWRT and DSST scores were predictive. Our findings support the contention that cognitive changes may precede clinical dementia by a decade or more.

Copyright $\odot 2012$ S. Karger AG, Basel

\section{Introduction}

Previous studies have examined the association between cognitive test scores measured at a single point in time and subsequent development of dementia [1-8]. Most studies have focused on cognitive function in the elderly ( $\geq 65$ years of age) [4-8] or have had short-term $(<10$ years) follow-up for dementia [4-7]. Few studies have examined an association between cognition measured in individuals $<65$ years of age and dementia later in life $[1,3,9]$ or examined the association of change in cognitive test scores with risk of dementia $[4,8]$. 
Our objective was to characterize the relationship of cognitive function to future dementia risk in the community-based Atherosclerosis Risk in Communities (ARIC) Study cohort. We examined the associations between cognitive function assessed at two time points (mean ages of 57 and 63 years) and the 6-year change in cognitive function with subsequent risk of dementia hospitalization. We also compared the associated short-term versus long-term risk of dementia.

\section{Materials and Methods}

\section{Study Population}

The ARIC Study is an ongoing community-based prospective cohort designed to study the etiology, natural history and consequences of atherosclerosis [10]. The study includes 15,792 middleaged adults from 4 US communities. There were 5 in-person visits; the first visit occurred in 1987-1989, followed by 3 subsequent visits occurring approximately 3 years apart, and a fifth visit which is currently under way. Cognitive functioning was assessed at 2 time points: visit 2 (1990-1992) and visit 4 (1996-1998). Of the 11,449 participants who attended both visits 2 and 4 , we further excluded those who were missing covariates of interest $(\mathrm{n}=$ 973), who self-identified as other than white or black race $(\mathrm{n}=28)$, who had a history of stroke prior to visit $4(\mathrm{n}=845)$, who had incomplete cognitive test data at visits 2 or $4(n=198)$, or who were hospitalized with dementia prior to visit $4(\mathrm{n}=6)$, leaving 9,399 participants included in the final sample.

\section{Measures of Cognitive Function}

Three neuropsychological tests were used: the Delayed Word Recall Test (DWRT), the Digit Symbol Substitution Test (DSST), and the Word Fluency Test (WFT) [11-13]. These tests have been described in detail elsewhere $[2,14]$.

\section{Incident Dementia Hospitalization}

The ARIC Study obtains hospitalization information from annual telephone contact with study participants and through active surveillance of all hospitalizations in the study communities. Follow-up was available up until December 31, 2008. We defined time to first hospitalization with an ICD-9 code for dementia using the following ICD-9 codes (listed anywhere in the hospital discharge record): Alzheimer's disease (331.0), vascular dementia (290.4) or dementia of other etiology, including senile, presenile, and frontotemporal dementias, and dementias secondary to a general medical condition (e.g. Parkinson's disease) (290.0, 290.1, 290.2, 290.3, 290.9, 294.1, 294.2, 294.8, 294.9, 331.1, 331.2, 331.8, 331.9) [2]. We have previously reported age- and race-specific rates of hospitalization with dementia [2].

\section{Covariates}

All covariates used in the regression models were assessed at visit 2 and visit 4, except education, which was assessed at visit 1. Covariates included: age (years), gender, race/center (Maryland whites; Minnesota whites; North Carolina whites; North Carolina blacks; Mississippi blacks), education (<high school; high school or equivalent; college or professional), income (USD $<35,000$ /year; USD $\geq 35,000$ /year; unknown), diabetes (self-report, medication use, or fasting blood glucose $\geq 126 \mathrm{mg} / \mathrm{dl}$ ), body mass index, cigarette smoking (current; former; never), alcohol consumption (current; former; never), total and high-density lipoprotein cholesterol (mg/dl), hypertension (self-report, medication use, systolic blood pressure $\geq 140 \mathrm{~mm} \mathrm{Hg}$, or diastolic blood pressure $\geq 90 \mathrm{~mm} \mathrm{Hg}$ ) and APOE $\varepsilon 4$ genotype $(0,1$, or $2 \varepsilon 4$ alleles).

\section{Statistical Analysis}

ARIC visit 4 is the baseline for the present study, but we also used the cognitive test scores at visit 2 to examine the prior trajectory of cognitive function. Characteristics of the population at visit 4 are adjusted for age, gender, and race/center.

The visit 2 and visit 4 cognitive test scores of participants who developed dementia were stratified by the number of years (in 2.5year intervals) prior to dementia hospitalization that the cognitive testing occurred. For each time interval, the adjusted mean $[95 \%$ confidence interval (CI)] visit 2 and visit 4 cognitive test scores were calculated and plotted. We also calculated and plotted adjusted mean (95\% CI) visit 2 and visit 4 cognitive test scores for noncases.

We divided visit 4 cognitive test scores into approximate tertiles and used the same score cutoff points to create three groups of visit 2 test scores. Since most participants had cognitive test scores in the nonimpaired range and the range of test scores was narrow, each tertile does not contain exactly the same number of participants. We divided follow-up time at 6.5 years after visit 4 to investigate longer-term risk of incident dementia. To compare short-term versus long-term risk of dementia, we compared the association with cognitive test score tertiles at visit 4 (short-term) and visit 2 (long-term). To assess the association with 6-year change in cognition (movement between tertiles from visit 2 to visit 4$)$, we modeled each of the 9 categories $(3 \times 3$ matrix $)$ of score tertile changes from visit 2 and visit 4 . We estimated adjusted hazard ratios (HRs) and their 95\% CIs for incident dementia hospitalization using Cox proportional hazards regression. We tested for interactions by gender and race/center. We repeated the analyses excluding individuals with low cognitive scores (lowest 5\%) on each test at the first time point (visit 2) to assess the effect of removing scores that have restricted ability to show decline $(\mathrm{n}=$ 8,714 ) [2]. We also performed a sensitivity analysis to assess the relationship of incomplete data on the cognitive tests $(n=198)$ with incident dementia hospitalization.

All reported $p$ values are two-sided and $p<0.05$ was considered statistically significant. Analyses were performed using Stata Version 11 [15].

\section{Results}

Characteristics of the 9,399 study participants at visit 4 stratified by dementia case status are shown in table 1 . Overall, 249 hospitalizations with an ICD-9 code for dementia occurred during a median of 10.2 years of followup after visit 4 . Of the 249 incident dementia hospitalizations, 67 (26.9\%) were coded as Alzheimer's disease, 23 
(9.2\%) were coded as vascular dementia, whereas 159 (63.9\%) were coded only as dementia without a specified etiology. Participants with incident dementia hospitalization were older at visit 4 (mean 68 years vs. 63 years) and more likely to be of black race (32 vs. $20 \%$ ) than noncases. Even after demographic adjustment, they were more likely to have diabetes ( 27 vs. $17 \%, \mathrm{p}<0.001)$ and hypertension (53 vs. $45 \%, \mathrm{p}=0.017$ ). During follow-up (after visit 4), of the 9,150 noncases, 1,106 participants died and 640 were lost to follow-up or refused further contact. Participants who died during follow-up were older and had lower average cognitive test scores at both visit 2 and visit 4 compared to those who remained in the study (online suppl. table 1; for all online suppl. material, see www. karger.com/doi/10.1159/000342308). Participants who were lost to follow-up or refused further contact were younger than those who remained in the study; they also had slightly lower average cognitive scores than those with complete follow-up.

Figure 1 shows the age-, gender-, and race/center-adjusted mean (95\% CI) cognitive test scores at both visits 2 and 4 for the 249 dementia cases and the 9,150 noncases. On all cognitive tests, dementia cases tended to have lower scores at both visits 2 and 4 than noncases. Among noncases, there was a small, but significant, decline in score over the 6-year period between visits on the DSST (mean visit 2 score $=47.0$, mean visit 4 score $=44.6$ ), and small nonsignificant declines in the DWRT and WFT. Among dementia cases, scores on cognitive tests given $<10$ years before dementia hospitalization were lower than scores on tests given $\geq 10$ years before dementia hospitalization. These patterns were more pronounced for the DWRT and the DSST than for the WFT.

There were 142 dementia hospitalizations that occurred $\geq 6.5$ years after visit 4 . The adjusted hazard ratios (HRs) (95\% CIs) for dementia hospitalization occurring $\geq 6.5$ years after visit 4 by tertile of cognitive test score at visits 2 and 4 and by category of change in tertile of cognitive test score from visit 2 to visit 4 are shown in table 2 (DWRT), table 3 (DSST), and online supplementary table 2 (WFT). As seen in the margins of each table, visit 4 scores were more strongly associated with incident dementia hospitalization than visit 2 scores. But visit 2 scores, despite being less proximate to the event, were also associated with DWRT and DSST. As shown in the interior cells of the tables, compared to those remaining in tertile 1 on the DWRT at both visits, either being in tertile 2 or 3 at both visits [diagonals: tertile 2, $\mathrm{HR}=3.44(95 \%$ $\mathrm{CI}=1.21-9.79)$; tertile $3, \mathrm{HR}=7.53(95 \% \mathrm{CI}=2.61-21.77)]$ or declining tertiles between visits [below the diagonals:
Table 1. Characteristics of ARIC participants at visit 4 stratified by dementia hospitalization status

\begin{tabular}{|c|c|c|}
\hline & $\begin{array}{l}\text { Participants } \\
\text { without incident } \\
\text { dementia } \\
\text { hospitalization } \\
(\mathrm{n}=9,150)\end{array}$ & $\begin{array}{l}\text { Participants with } \\
\text { incident } \\
\text { dementia } \\
\text { hospitalization } \\
(\mathrm{n}=249)\end{array}$ \\
\hline Mean age $\pm S D$, years & $62.6 \pm 5.6$ & $67.8 \pm 4.8$ \\
\hline Females, n & $5,159(56.4 \%)$ & $131(52.6 \%)$ \\
\hline \multicolumn{3}{|l|}{ Race, $\mathrm{n}$} \\
\hline Caucasian & $7,364(80.5 \%)$ & $170(68.3 \%)$ \\
\hline African American & $1,786(19.5 \%)$ & $79(31.7 \%)$ \\
\hline \multicolumn{3}{|l|}{ Education $^{\mathrm{a}}, \%$} \\
\hline $\begin{array}{l}<\text { High school } \\
\text { High school or }\end{array}$ & $15.9(2.9)$ & $20.3(14.5)$ \\
\hline vocational school & $42.7(2.1)$ & $39.3(13.5)$ \\
\hline $\begin{array}{l}\text { College, graduate, } \\
\text { or professional school }\end{array}$ & $39.9(2.2)$ & $36.9(13.6)$ \\
\hline \multicolumn{3}{|l|}{ Cigarette smoking status ${ }^{\mathrm{a}}, \%$} \\
\hline Current smoker & $13.5(3.1)$ & $18.5(17.6)$ \\
\hline Former smoker & $43.7(2.2)$ & $44.1(13.3)$ \\
\hline Never smoker & $41.2(2.2)$ & $36.4(13.7)$ \\
\hline \multicolumn{3}{|l|}{ Alcohol use status ${ }^{\mathrm{a}}, \%$} \\
\hline Current alcohol use & $50.9(2.2)$ & $43.3(13.9)$ \\
\hline Former alcohol use & $28.5(2.3)$ & $35.1(13.3)$ \\
\hline Never alcohol use & $18.2(3.5)$ & $22.1(18.3)$ \\
\hline Mean body mass index ${ }^{\mathrm{a}}, \mathrm{kg} / \mathrm{m}^{2}$ & $28.7(0.1)$ & $28.7(0.4)$ \\
\hline Mean total cholesterol ${ }^{\mathrm{a}}, \mathrm{mg} / \mathrm{dl}$ & $201.1(0.4)$ & $193.6(2.3)$ \\
\hline Mean HDL cholesterola ${ }^{\mathrm{a}}, \mathrm{mg} / \mathrm{dl}$ & $50.1(0.2)$ & $51.3(1.0)$ \\
\hline Hypertension $^{\mathrm{a}}, \%$ & $45.2(0.02)$ & $53.3(0.13)$ \\
\hline Diabetes $^{\mathrm{a}}, \%$ & $17.0(0.03)$ & $26.7(0.14)$ \\
\hline \multicolumn{3}{|c|}{ Mean cognitive test score at visit $2^{\mathrm{a}}$} \\
\hline Delayed word recall & $6.77(0.01)$ & $6.44(0.09)$ \\
\hline Digit symbol substitution & $46.9(0.1)$ & $42.8(0.7)$ \\
\hline Word fluency test & $34.5(0.1)$ & $33.7(0.8)$ \\
\hline \multicolumn{3}{|c|}{ Mean cognitive test score at visit $4^{\mathrm{a}}$} \\
\hline Delayed word recall & $6.66(0.02)$ & $5.60(0.09)$ \\
\hline Digit symbol substitution & $44.5(0.1)$ & $37.1(0.7)$ \\
\hline Word fluency test & $34.0(0.1)$ & $31.2(0.8)$ \\
\hline
\end{tabular}

Figures in parentheses indicate SE, unless indicated otherwise.

a Age-, gender-, and race/center-adjusted.

change from tertile 1 to 2 , $\mathrm{HR}=3.36(95 \% \mathrm{CI}=1.10-$ 10.27); change from tertile 1 to $3, \mathrm{HR}=6.45$ (95\% CI $=$ 1.80-23.08); change from tertile 2 to $3, \mathrm{HR}=5.39(95 \%$ $\mathrm{CI}=1.85-15.67)]$ were significantly associated with incident dementia hospitalization. Improving tertiles between visits (above the diagonals) tended to be associated with incident dementia hospitalization, but these results were largely nonsignificant. Similar significant patterns were seen on the DSST (table 3) and the WFT (online 


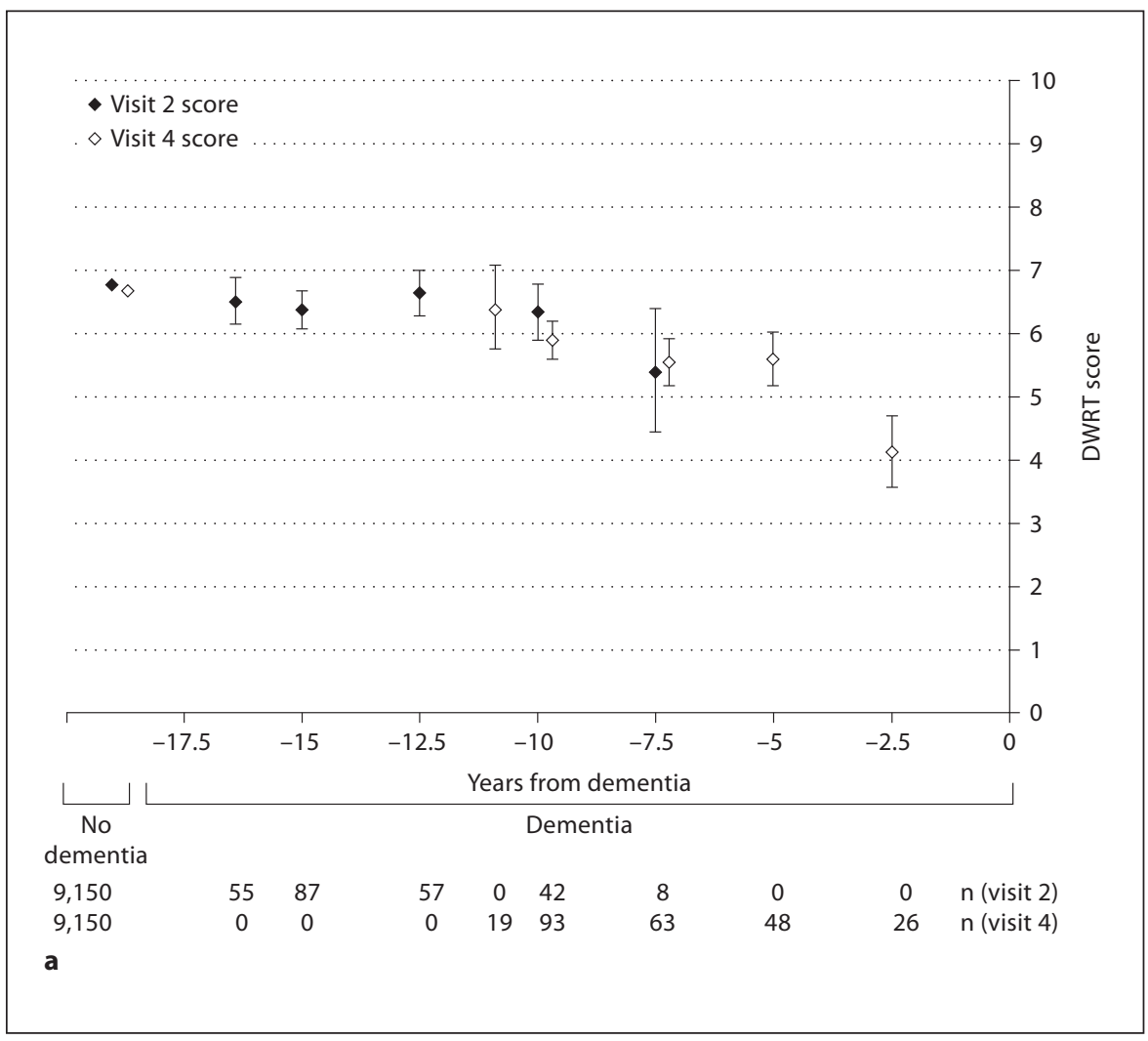

Fig. 1. Age-, gender-, and race/center-adjusted mean (95\% CI) cognitive test scores stratified by dementia status. Scores for participants who develop dementia are further stratified by the number of years (in 2.5-year intervals) from dementia diagnosis that corresponds to the test score. a DWRT. b DSST.

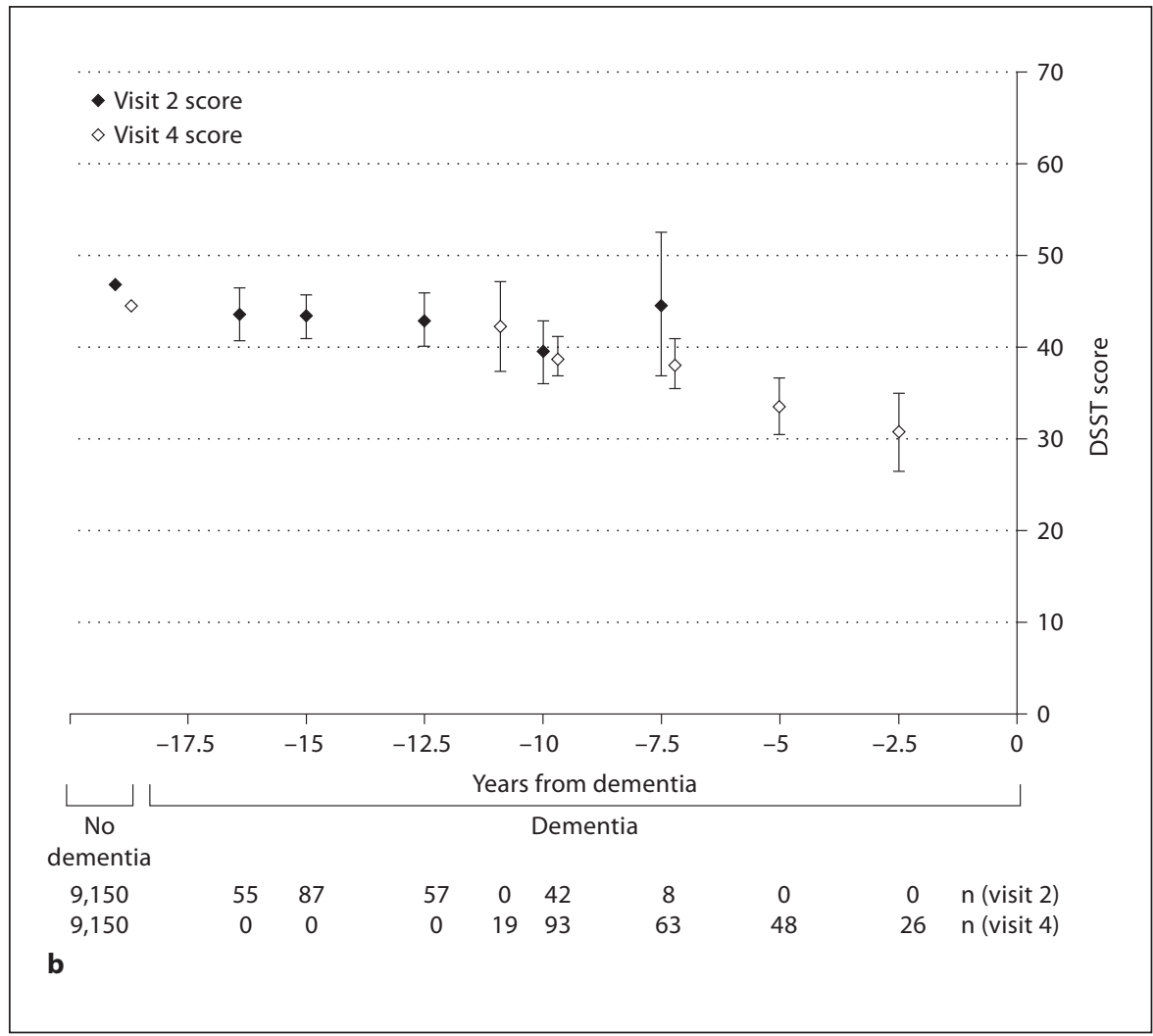


Fig. 1. Age-, gender-, and race/center-adjusted mean (95\% CI) cognitive test scores stratified by dementia status. Scores for participants who develop dementia are further stratified by the number of years (in 2.5-year intervals) from dementia diagnosis that corresponds to the test score. c WFT.

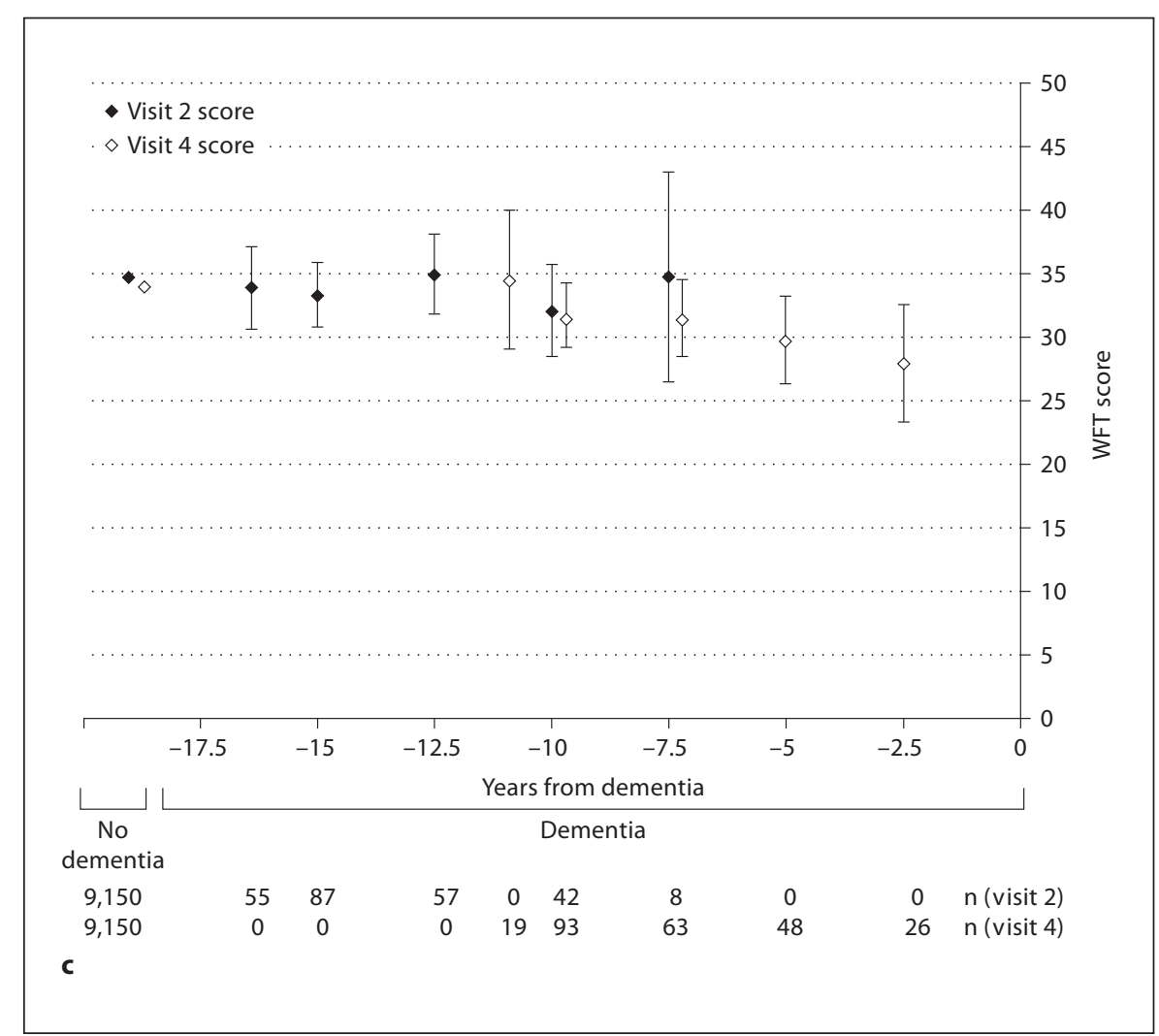

Table 2. Adjusted ${ }^{\mathrm{a}}$ HRs (95\% CI) for incident dementia occurring $\geq 6.5$ years after visit 4 by category of DWRT score at visits 2 and 4

\begin{tabular}{|c|c|c|c|c|}
\hline Visit 4 score & $\begin{array}{l}\text { category } 1 \\
\text { (score } 8-10)\end{array}$ & $\begin{array}{l}\text { category } 2 \\
(\text { score } 6-<8)\end{array}$ & $\begin{array}{l}\text { category } 3 \\
(\text { score } 0-<6)\end{array}$ & \\
\hline $\begin{array}{l}\text { Category } 1 \\
(\text { score } 8-10)\end{array}$ & $\begin{array}{l}1.00 \text { (reference) } \\
4 / 1,488\end{array}$ & $\begin{array}{l}2.56(0.80-8.18) \\
10 / 1,183\end{array}$ & $\begin{array}{l}- \\
0 / 135\end{array}$ & $\begin{array}{l}1.00 \text { (reference) } \\
14 / 2,806\end{array}$ \\
\hline $\begin{array}{l}\text { Category } 3 \\
(\text { score } 0-<6)\end{array}$ & $\begin{array}{l}6.45(1.80-23.08)^{*} \\
6 / 214\end{array}$ & $\begin{array}{l}5.39(1.85-15.67)^{*} \\
27 / 971\end{array}$ & $\begin{array}{l}7.53(2.61-21.77)^{*} \\
36 / 872\end{array}$ & $\begin{array}{l}3.86(2.12-7.05)^{*} \\
69 / 2,057\end{array}$ \\
\hline & $\begin{array}{l}1.00 \text { (reference) } \\
24 / 2,968\end{array}$ & $\begin{array}{l}1.37(0.86-2.20) \\
71 / 4,709\end{array}$ & $\begin{array}{l}1.77(1.05-2.98)^{*} \\
47 / 1,722\end{array}$ & $142 / 9,399$ \\
\hline
\end{tabular}

Additional data represent number of events/number of participants in each group. ${ }^{*} \mathrm{p}<0.05$.

${ }^{a}$ Model is adjusted for age (years), gender, race/center (Maryland whites; Minnesota whites; North Carolina whites; North Carolina blacks; Mississippi blacks), education ( $<$ high school; high school or equivalent; college or professional), income (USD
$<35,000$ /year; USD $\geq 35,000$ /year; unknown), diabetes, body mass index, cigarette smoking (current; former; never), alcohol consumption (current; former; never), total cholesterol (mg/dl), HDL cholesterol (mg/dl), hypertension, and APOE $\varepsilon 4$ genotype $(0,1$, or $2 \varepsilon 4$ alleles). 
Table 3. Adjusted ${ }^{\mathrm{a}}$ hazard ratios $(95 \% \mathrm{CI})$ for incident dementia occurring $\geq 6.5$ years post visit 4 by category of DSST score at visits 2 and 4

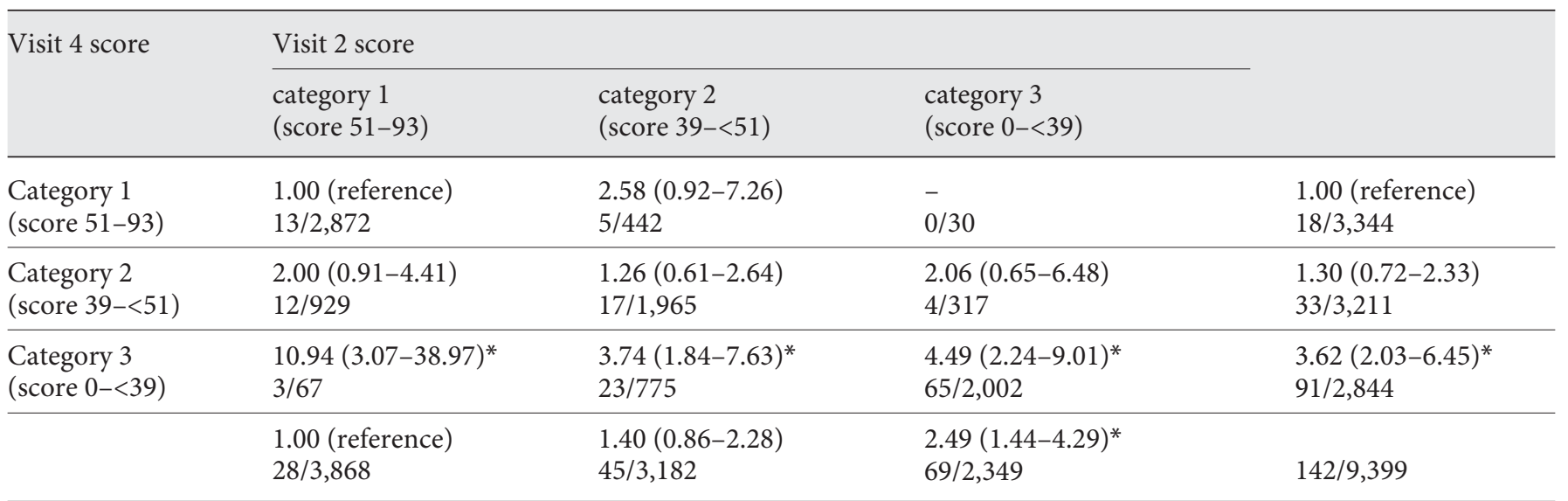

Additional data represent number of events/number of participants in each group. ${ }^{*} \mathrm{p}<0.05$.

a Model is adjusted for age (years), gender, race/center (Maryland whites; Minnesota whites; North Carolina whites; North Carolina blacks; Mississippi blacks), education (<high school; high school or equivalent; college or professional), income (USD
$<35,000$ /year; USD $\geq 35,000$ /year; unknown), diabetes, body mass index, cigarette smoking (current; former; never), alcohol consumption (current; former; never), total cholesterol (mg/dl), HDL cholesterol (mg/dl), hypertension, and APOE $\varepsilon 4$ genotype $(0,1$, or $2 \varepsilon 4$ alleles). suppl. table 2), but associations for WFT were not statistically significant.

In our sensitivity analyses excluding individuals with low cognitive scores (lowest 5\%) on each test at visit 2 , there were 122 dementia hospitalizations that occurred $\geq 6.5$ years after visit 4 . On all tests, in the interior cells of the tables (change in score from visit 2 to 4), the HRs tended to be stronger compared to the main analysis, and the HRs in the margins of the table (visits 2 and 4 separately) were not appreciably altered. In sensitivity analyses, having incomplete cognitive test data was not significantly associated with incident dementia hospitalization [HR $=1.38(95 \% \mathrm{CI}=0.58-3.27)]$, but our power to detect an association was low due to the small numbers $(n=198)$ of eligible participants with incomplete cognitive testing data.

\section{Discussion}

In this community-based population, cognitive scores at mean ages 57 and 63 years, and 6-year change in cognitive scores were associated with long-term risk of dementia hospitalization. In particular, large 6-year declines in scores on the DWRT and DSST were associated with risk for dementia hospitalization occurring $\geq 6.5$ years later.
Although our dementia definition based on hospital discharge codes likely underestimates the true prevalence of dementia, our findings support evidence that impairment on cognitive tests starts long before dementia onset.

Although there are many presentations of dementia, dysfunction in memory is very common [16]. In our study, the DWRT, which is a test of recent memory, was most strongly associated with overall dementia risk. The DSST, which is a test of executive function and processing speed, was also strongly associated with dementia risk in our study population, consistent with accumulating evidence that other tasks, in addition to memory tasks, are impaired in dementia $[1,4,8,17,18]$. In our population, performance on the WFT, a test of expressive language, was not associated with incident dementia hospitalization, which may be due to the younger age or other features unique to the ARIC cohort.

Our results are consistent with previous studies that have shown an association between cognitive test score(s) and short-term risk of dementia in mostly older adults [47] and long-term risk of dementia in predominantly younger or middle-aged adults $[1-3,8,9]$. However, previous studies have been limited by a single assessment of cognitive function [1-3], short length of follow-up [4-7], or study populations limited primarily to the elderly $[1,4-8]$. In our study, we compared two assessments of cognition, 
occurring approximately 6 years apart, and change in cognition over this period in a community-based population.

Our analyses looking at the trajectory of scores for participants who develop dementia (fig. 1) showed that lower cognitive test scores measured long before dementia hospitalization predict dementia risk [8]. We also found that the 6-year change in score may be more predictive of subsequent dementia hospitalization than a single assessment. An advantage to using change in cognitive test score over time for prediction is greater specificity, since change is likely to be less biased by cultural confounding factors and less affected by measurement error if the errors occurring over time are correlated [19, 20]. Thus, the strong relationship between the 6-year decline in score and incident dementia hospitalization suggests that changes in cognition are due to actual changes in brain functioning, not to residual confounding or measurement errors. However, we also observed a nonsignificant trend towards an association between 6-year improvement in score and incident dementia hospitalization. This may be a reflection of a small number of participants who performed better by chance or may reflect persons with true cognitive impairment with a variable course whereby cognitive function is better some days than others [21].

Important limitations of our study include a cognitive test battery comprised of 3 tests and the use of ICD-9 hospitalization codes to define incident dementia. We did not have the information needed to determine if dementia was the primary reason for hospitalization. Dementia hospitalization may be a highly specific index of dementia in the community (aside from misdiagnosis of temporary conditions such as delirium), but it likely disproportionately identifies the most severe cases of dementia and cases occurring in individuals with multiple comorbidities. In a prior analysis of ARIC data [2], age-specific incidence rates of dementia were also noted to be lower than in previous studies $[22,23]$. Therefore, the use of dementia hospitalization as our outcome likely provides conservative estimates of the association between cognitive performance and dementia. Due to the small number of dementia cases $(n=249)$ in our population, we were not able to perform separate analyses stratified by dementia types (i.e., Alzheimer's disease vs. vascular dementia, etc.). Additionally, the distribution of dementia subtypes based on ICD codes is not consistent with what we would expect if the cases had been subjected to standardized diagnoses [24]; in our study, only $27 \%$ of cases were attributed to Alzheimer's disease, while $64 \%$ of cases were attributed to dementia of other unspecified etiology. This reflects a limitation in the use of ICD-9 discharge codes. Strengths of this study include the large, community-based study population with long-term follow-up, two assessments of cognition 6 years apart, and comprehensive assessment of potential confounders.

\section{Conclusion}

Our results contribute to the evidence that a single measure of cognitive function and change in cognitive function over time are associated with long-term risk of dementia. Change in cognitive scores over time tended to be more associated with later dementia hospitalization than a single cognitive test score alone. Our findings highlight important implications for clinical practice and for the design of dementia prevention and treatment trials, including the need for repeated cognitive assessments over time and the importance of enrolling participants many years before the onset of clinical dementia, prior to the subtle cognitive function changes that precede dementia onset.

\section{Acknowledgements}

The Atherosclerosis Risk in Communities Study is carried out as a collaborative study supported by National Heart, Lung, and Blood Institute contracts (HHSN268201100005C, HHSN268201100006C, HHSN268201100007C, HHSN268201100008C, HHSN268201100009C, HHSN268201100010C, HHSN268201$100011 \mathrm{C}$, and HHSN268201100012C). The authors thank the staff and participants of the ARIC study for their important contributions. Andrea L.C. Schneider was supported by NIH/NIDDK training grant T32 DK062707.

\section{Disclosure Statement}

None.

$\begin{aligned} \text { References } & \text { Elias MF, Beiser A, Wolf PA, Au R, White RF, } \\ & \text { D’Agostino RB: The preclinical phase of Alz- } \\ & \text { heimer disease: a 22-year prospective study } \\ & \text { of the Framingham Cohort. Arch Neurol } \\ & 2000 ; 57: 808-813 \text {. } \\ 2 & \text { Alonso A, Mosley TH Jr, Gottesman RF, } \\ & \text { Catellier D, Sharrett AR, Coresh J: Risk of } \\ & \text { dementia hospitalisation associated with } \\ & \text { cardiovascular risk factors in midlife and } \\ & \text { older age: the Atherosclerosis Risk in Com- } \\ & \text { munities (ARIC) study. Jeurol Neurosurg } \\ & \text { Psychiatry 2009;80:1194-1201. }\end{aligned}$


-3 Riley KP, Snowdon DA, Desrosiers MF, Markesbery WR: Early life linguistic ability, late life cognitive function, and neuropathology: findings from the Nun Study. Neurobiol Aging 2005;26:341-347.

-4 Amieva H, Jacqmin-Gadda H, Orgogozo JM Le Carret N, Helmer C, Letenneur L, Barberger-Gateau P, Fabrigoule C, Dartigues JF: The 9 year cognitive decline before dementia of the Alzheimer type: a prospective population-based study. Brain 2005;128(Pt 5):10931101.

$\checkmark 5$ Kuller LH, Lopez OL, Newman A, Beauchamp NJ, Burke G, Dulberg C, Fitzpatrick A, Fried L, Haan MN: Risk factors for dementia in the cardiovascular health cognition study. Neuroepidemiology 2003;22:1322.

6 Chen P, Ratcliff G, Belle SH, Cauley JA, DeKosky ST, Ganguli M: Patterns of cognitive decline in presymptomatic Alzheimer disease: a prospective community study. Arch Gen Psychiatry 2001;58:853-858.

7 Backman L, Small BJ, Fratiglioni L: Stability of the preclinical episodic memory deficit in Alzheimer's disease. Brain 2001; 124(Pt 1):96-102.

-8 Amieva H, Le Goff M, Millet X, Orgogozo JM, Peres K, Barberger-Gateau P, JacqminGadda H, Dartigues JF: Prodromal Alzheimer's disease: successive emergence of the clinical symptoms. Ann Neurol 2008;64: 492-498.
9 Singh-Manoux A, Kivimaki M, Glymour MM, Elbaz A, Berr C, Ebmeier KP, Ferrie JE, Dugravot A: Timing of onset of cognitive decline: results from Whitehall II prospective cohort study. BMJ 2011;344:d7622.

10 The Atherosclerosis Risk in Communities (ARIC) Study: design and objectives. The ARIC investigators. Am J Epidemiol 1989; 129:687-702.

11 Knopman DS, Ryberg S: A verbal memory test with high predictive accuracy for dementia of the Alzheimer type. Arch Neurol 1989;46:141-145.

12 Wechsler D: Manual for the Wechsler Adult Intelligence Scale - Revised. New York, Psychological Corporation, 1981.

13 Benton AL, Hamsher K: Multilingual Aphasia Examination, ed 2. Iowa City, AJA Associates, 1989.

14 Christman AL, Matsushita K, Gottesman RF, Mosley T, Alonso A, Coresh J, HillBriggs F, Sharrett AR, Selvin E: Glycated haemoglobin and cognitive decline: the Atherosclerosis Risk in Communities (ARIC) study. Diabetologia 2011;54:1645-1652.

15 Stata: Stata Statistical Software: Release 11. College Station, StataCorp, 2009

16 Zhang Y, Han B, Verhaeghen P, Nilsson LG: Executive functioning in older adults with mild cognitive impairment: MCI has effects on planning, but not on inhibition. Neuropsychol Dev Cogn B Aging Neuropsychol Cogn 2007; 14:557-570.

-17 Albert MS, Moss MB, Tanzi R, Jones K: Preclinical prediction of $\mathrm{AD}$ using neuropsychological tests. J Int Neuropsychol Soc 2001; 7:631-639.

18 Marshall PS, Watson D, Steinberg P, Cornblatt B, Peterson PK, Callies A, Schenck CH: An assessment of cognitive function and mood in chronic fatigue syndrome. Biol Psychiatry 1996;39:199-206.
9 Geiss LS, Rolka DB, Engelgau MM: Elevated blood pressure among US adults with diabetes, 1988-1994. Am J Prev Med 2002;22:4248 .

20 Song Y, Manson JE, Buring JE, Liu S: A prospective study of red meat consumption and type 2 diabetes in middle-aged and elderly women: the women's health study. Diabetes Care 2004;27:2108-2115.

21 Bracco L, Gallato R, Grigoletto F, Lippi A, Lepore V, Bino G, Lazzaro MP, Carella F, Piccolo T, Pozzilli C, et al: Factors affecting course and survival in Alzheimer's disease. A 9-year longitudinal study. Arch Neurol 1994;51:1213-1219.

22 Fitzpatrick AL, Kuller LH, Ives DG, Lopez OL, Jagust W, Breitner JC, Jones B, Lyketsos C, Dulberg C: Incidence and prevalence of dementia in the Cardiovascular Health Study. J Am Geriatr Soc 2004;52:195-204.

23 Tang MX, Cross P, Andrews H, Jacobs DM, Small S, Bell K, Merchant C, Lantigua R, Costa R, Stern Y, et al: Incidence of AD in African-Americans, Caribbean Hispanics, and Caucasians in northern Manhattan. Neurology 2001;56:49-56.

24 Plassman BL, Langa KM, McCammon RJ, Fisher GG, Potter GG, Burke JR, Steffens DC, Foster NL, Giordani B, Unverzagt FW, et al: Incidence of dementia and cognitive impairment, not dementia in the united states. Ann Neurol 2011;70:418-426. 